\title{
Structure dependent electrochemical performance of Li-rich layered oxides in lithium-ion batteries
}

Fang $\mathrm{Fu}^{\mathrm{a}}$, Yuze $\mathrm{Yao}^{\mathrm{a}}$, Haiyan Wang ${ }^{\mathrm{a}, \mathrm{b}}$, Gui-Liang $\mathrm{Xu}^{\mathrm{c}}$, Khalil Amine ${ }^{\mathrm{c}, *}$, Shi-Gang $\operatorname{Sun}^{\mathrm{d}, *}$, Minhua Shao ${ }^{\mathrm{a}, \mathrm{e}, *}$

${ }^{\mathrm{a}}$ Department of Chemical and Biomolecular Engineering, The Hong Kong University of Science and Technology, Clear Water Bay, Kowloon, Hong Kong, P.R. China

${ }^{\mathrm{b}}$ College of Chemistry and Chemical Engineering, Central South University, Changsha, 410083, P.R. China

${ }^{\mathrm{c} C h e m i c a l ~ S c i e n c e s ~ a n d ~ E n g i n e e r i n g ~ D i v i s i o n, ~ A r g o n n e ~ N a t i o n a l ~ L a b o r a t o r y, ~} 9700$ South Cass Avenue, Lemont, IL 60439, USA

${ }^{\mathrm{d}}$ State key laboratory of physical chemistry of solid surfaces, Department of Chemistry, College of Chemistry and Chemical Engineering, Xiamen University, Xiamen 361005, China

${ }^{\mathrm{e}}$ Energy Institute, Hong Kong University of Science and Technology, Clear Water Bay, Kowloon, Hong Kong, P.R. China

*E-mail: amine@anl.gov (K. Amine); sgsun@xmu.edu.cn (S.G. Sun); kemshao@ust.hk (M.H. Shao).

\begin{abstract}
:
Rational and precise control of the structure and dimension of electrode materials is an efficient way to improve their electrochemical performance. In this work, solvothermal or co-precipitation method is used to synthesize lithium-rich layered oxide materials of $\mathrm{Li}_{1.2} \mathrm{Mn}_{0.56} \mathrm{Co}_{0.12} \mathrm{Ni}_{0.12} \mathrm{O}_{2}$ (LLO) with various morphologies and structures, including microspheres, microrods, nanoplates, and irregular nanoparticles.


These materials exhibit strong structure-dependent electrochemical properties. The porous hierarchical structured LLO microrods exhibit the best performance, delivering a discharge capacity of $264.6 \mathrm{mAh} \mathrm{g}^{-1}$ at $0.5 \mathrm{C}$ with over $91 \%$ retention after 100 cycles. At a high rate of $5 \mathrm{C}$, a high discharge capacity of $173.6 \mathrm{mAh} \mathrm{g}^{-1}$ can be achieved. This work reveals the relationship between the morphologies and electrochemical properties of LLO cathode materials, and provides a feasible approach to fabricating robust and high-performance electrode materials for lithium-ion batteries.

Key words: Li-rich layered oxide; stability; cathode; lithium-ion battery.

\section{Introduction}

Lithium-ion batteries (LIBs) have gained huge commercial success in portable electronics and are the main energy storage device in electric vehicles [1]. However, these batteries require further improvement before they can bring about widespread deployment of electric vehicles. The performance of LIBs is mainly determined by the properties of electrode materials, especially cathode materials [2]. Thus, advanced cathode materials with significantly higher capacities and stability are urgently needed. Lithium-rich layered oxides, either as a solid solution or as a nano-composite of layered $\mathrm{Li}_{2} \mathrm{MnO}_{3}$ and $\mathrm{Li}(\mathrm{TM}) \mathrm{O}_{2}(\mathrm{TM}=\mathrm{Mn}, \mathrm{Co}, \mathrm{Ni})$, are believed to be a promising candidate of cathode material for future LIBs on account of their high specific capacity (typically $>250 \mathrm{mAh} \mathrm{g}^{-1}$ ) and low cost [3-4]. However, the implementation of these materials in practical LIBs has been impeded by several obstacles, including poor long-term performance, low rate capability, and voltage fading [5-6]. These issues are caused by (i) instability of the electrode/electrolyte interface under high potential, (ii) low ionic/electronic conductivity of the $\mathrm{Li}_{2} \mathrm{MnO}_{3}$ component, and (iii) structural transformation from the layered to spinel phase during cycling. To address these problems, researchers have developed many strategies, such as surface modification [7-8], heteroatom doping [9-10], composition optimization [11-12], and

increase of the $\mathrm{Li}^{+}$diffusion channels [13]. Despite encouraging progress, these 
cathode materials still can't meet the requirements for LIB electric-vehicle applications.

The properties of electrode materials depend highly on crystallite size, shape, composition, and architecture [14]. Thus, morphology control would be a powerful way to optimize the performance of the Li-rich layered cathode materials. Nevertheless, controlling the shape and structure of Li-rich layered oxides during synthesis is challenging because of the complex chemical compositions involved and the need for prolonged calcination at high temperature. Lithium-rich layered cathode materials are usually composed of at least two transition-metal elements. Incorporating different components with distinct physical and chemical properties to form various structures and morphologies of Li-rich layered cathode materials is difficult because of the different crystallization and crystal growth behavior [15]. Despite recent studies on electrochemical performance of Li-rich layered cathode materials with various structures $[13,16,17]$, the systematic study on shape evolution from 1D rod-like structure to 2D plate-like and 3D sphere-like structures, and the relationship between these structures and electrochemical properties have not been reported yet.

In this work, we conducted a careful study on the correlation between the morphology and performance of $\mathrm{Li}_{1.2} \mathrm{Mn}_{0.56} \mathrm{Co}_{0.12} \mathrm{Ni}_{0.12} \mathrm{O}_{2}$ (LLO) in LIBs. Microspheres, microrods, nanoplates, and irregular particles were synthesized via a solvothermal or co-precipitation method by carefully controlling the types of solvents and metal precursors. We found that an LLO microrod cathode material with a porous hierarchical structure exhibits the best electrochemical performance. It achieved outstanding discharge capacity (264.6 $\mathrm{mAh} \mathrm{g}^{-1}$ at $\left.0.5 \mathrm{C}\right)$, cyclability (241.1 $\mathrm{mAh} \mathrm{g}^{-1}$ after 100 cycles at $0.5 \mathrm{C}$ ), and rate capability (148.1 $\mathrm{mAh} \mathrm{g}^{-1}$ at $8 \mathrm{C}$ ). These results demonstrate that structure engineering of these active materials can lead to greatly improved electrochemical performance.

\section{Experimental}

Preparation of LLO microspheres: LLO microspheres were prepared by a 
solid-state reaction between the $\mathrm{Ni}-\mathrm{Co}-\mathrm{Mn}$ carbonate precursor and $\mathrm{LiOH} \cdot \mathrm{H}_{2} \mathrm{O}$. The Ni-Co-Mn carbonate precursor was prepared by a solvothermal method. In a typical synthesis, stoichiometric amounts of $\mathrm{Mn}\left(\mathrm{CH}_{3} \mathrm{COO}\right)_{2} \cdot 4 \mathrm{H}_{2} \mathrm{O}, \mathrm{Co}\left(\mathrm{NO}_{3}\right)_{2} \cdot 6 \mathrm{H}_{2} \mathrm{O}$, and $\mathrm{Ni}\left(\mathrm{NO}_{3}\right)_{2} \cdot 6 \mathrm{H}_{2} \mathrm{O}$ were mixed in $100 \mathrm{~mL}$ isopropanol. Then, $100 \mathrm{~mL}$ of $0.3 \mathrm{M}$ $\mathrm{NH}_{4} \mathrm{HCO}_{3}$ was added to the above solution dropwise. The mixture was transferred into a Teflon autoclave and kept at $180{ }^{\circ} \mathrm{C}$ for $12 \mathrm{~h}$. The resulting Ni-Co-Mn carbonate precursor was filtered, washed with deionized water, and dried at $100{ }^{\circ} \mathrm{C}$ for $12 \mathrm{~h}$ to remove adsorbed water. A mixture of the carbonate precursor and $\mathrm{LiOH} \cdot \mathrm{H}_{2} \mathrm{O}$ was preheated to $450{ }^{\circ} \mathrm{C}$ for $6 \mathrm{~h}$ and then heated at $900{ }^{\circ} \mathrm{C}$ for $12 \mathrm{~h}$ to obtain LLO microspheres.

Preparation of LLO microrods: LLO microrods were synthesized by solvothermal method. In a typical experiment, stoichiometric amounts of $\mathrm{LiCH}_{3} \mathrm{COO} \cdot 2 \mathrm{H}_{2} \mathrm{O}, \quad \mathrm{Mn}\left(\mathrm{CH}_{3} \mathrm{COO}\right)_{2} \cdot 4 \mathrm{H}_{2} \mathrm{O}, \quad \mathrm{Ni}\left(\mathrm{CH}_{3} \mathrm{COO}\right)_{2} \cdot 4 \mathrm{H}_{2} \mathrm{O}, \quad$ and $\mathrm{Co}\left(\mathrm{CH}_{3} \mathrm{COO}\right)_{2} \cdot 4 \mathrm{H}_{2} \mathrm{O}$ were dissolved in a mixed solvent consisting of ethanol and water in a 1:1 volume ratio. $\mathrm{A}_{2} \mathrm{C}_{2} \mathrm{O}_{4}$ solution $(0.12 \mathrm{~mol}$ in $80 \mathrm{~mL}$ of ethanol) was added dropwise into the mixed metal-acetate solution. The mixture was transferred to a Teflon autoclave and heated to $180{ }^{\circ} \mathrm{C}$ for $12 \mathrm{~h}$ for the solvothermal reaction. After the reaction, the resulting precipitates were obtained by solvent evaporation at $80{ }^{\circ} \mathrm{C}$. The as-synthesized precursor was first pre-treated at $450{ }^{\circ} \mathrm{C}$ for $6 \mathrm{~h}$ and then calcined at $900{ }^{\circ} \mathrm{C}$ for $12 \mathrm{~h}$ to obtain LLO microrods.

Preparation of LLO nanoplates: LLO nanoplates were synthesized by a solid-state reaction between $\mathrm{Ni}-\mathrm{Co}-\mathrm{Mn}$ hydroxide precursor and $\mathrm{LiOH} \cdot \mathrm{H}_{2} \mathrm{O}$. The precursor was prepared by a co-precipitation method. Stoichiometric amounts of $\mathrm{MnSO}_{4} \cdot 7 \mathrm{H}_{2} \mathrm{O}, \mathrm{NiSO}_{4} \cdot 6 \mathrm{H}_{2} \mathrm{O}$, and $\mathrm{CoSO}_{4} \cdot 7 \mathrm{H}_{2} \mathrm{O}$ were dissolved in deionized water. Both $2 \mathrm{M} \mathrm{NaOH}$ and the desired amount of $\mathrm{NH}_{3} \cdot \mathrm{H}_{2} \mathrm{O}$ were added separately into the solution under a nitrogen atmosphere. The co-precipitation temperature was held at $55{ }^{\circ} \mathrm{C}$, and the $\mathrm{pH}$ was kept at 11 . The $\mathrm{Mn}_{0.56} \mathrm{Ni}_{0.12} \mathrm{Co}_{0.12}(\mathrm{OH})_{0.8}$ precipitates were filtered, washed with deionized water, and dried at $100{ }^{\circ} \mathrm{C}$ overnight. The as-prepared $\mathrm{Mn}_{0.56} \mathrm{Ni}_{0.12} \mathrm{Co}_{0.12}(\mathrm{OH})_{0.8}$ was mixed with 5 wt \% excess $\mathrm{LiOH}$. After suitable grinding, the mixture was annealed in air under the same conditions described above. 
Preparation of LLO irregular particles: The synthesis of irregular particles was conducted under the same conditions as described in the preparation of microrods, except that pure water was used as the solvent.

Characterization: All products were characterized by scanning electron microscopy (SEM, JEOL-6300 and JEOL-6700F), energy dispersive X-ray spectroscopy (EDX, an EDX detector system attached to JEOL-6700F), and X-ray diffraction (XRD, Philips PW-1830 X-ray diffractometer, $\mathrm{Cu}$ K $\alpha$ radiation).

Electrochemical Tests: Cathodes were prepared by casting the slurry with a mixture of 80 wt.\% active material, 10 wt.\% carbon black (BP2000) (Cabot corporation, USA), and 10 wt.\% PVDF as the binder on an Al foil. Coin cells (2025 type) were assembled in an Ar-filled glovebox using Li foil as the anode and Celgard 2400 membrane as the separator. The typical mass loading of the active material in each electrode slice is $2.5-3 \mathrm{mg} \mathrm{cm}^{-2}$. The electrolyte was $1 \mathrm{M} \mathrm{LiPF}_{6}$ dissolved in ethylene carbonate, dimethylcarbonate, and diethyl carbonatewith a 1:1:1 volume ratio. The cells were charged and discharged between 2.0 and $4.8 \mathrm{~V}$ at different current rates on a battery test system (LAND-V34, Land Electronic Co., Ltd., Wuhan). Cyclic voltammogram (CV) and electrochemical impedance spectroscopy (EIS) measurements were conducted on an electrochemical workstation (CHI760, $\mathrm{CH}$ Instruments). The CV was obtained between 2.0 and $4.8 \mathrm{~V}$. The EIS was performed in the frequency range of $10 \mathrm{mHz}-100 \mathrm{kHz}$ with an amplitude of $5.0 \mathrm{mV}$.

\section{Results}

The morphology and microstructure of the LLO precursors and LLO were characterized by SEM. Figures 1a and b-c present SEM images of the spherical precursor and LLO product, respectively, prepared by the isopropanol-based solvothermal method. The Ni-Co-Mn carbonate precursor is composed of microspheres with a smooth surface and an average diameter of $\sim 1 \mu \mathrm{m}$ (Figure 1a). The XRD pattern shows a typical metal carbonate (Figure S1). After mixing with $\mathrm{LiOH} \cdot \mathrm{H}_{2} \mathrm{O}$ and being calcined at high temperature, the smooth precursor microspheres converted into hierarchical LLO microspheres. As seen in Figures 1b-c 

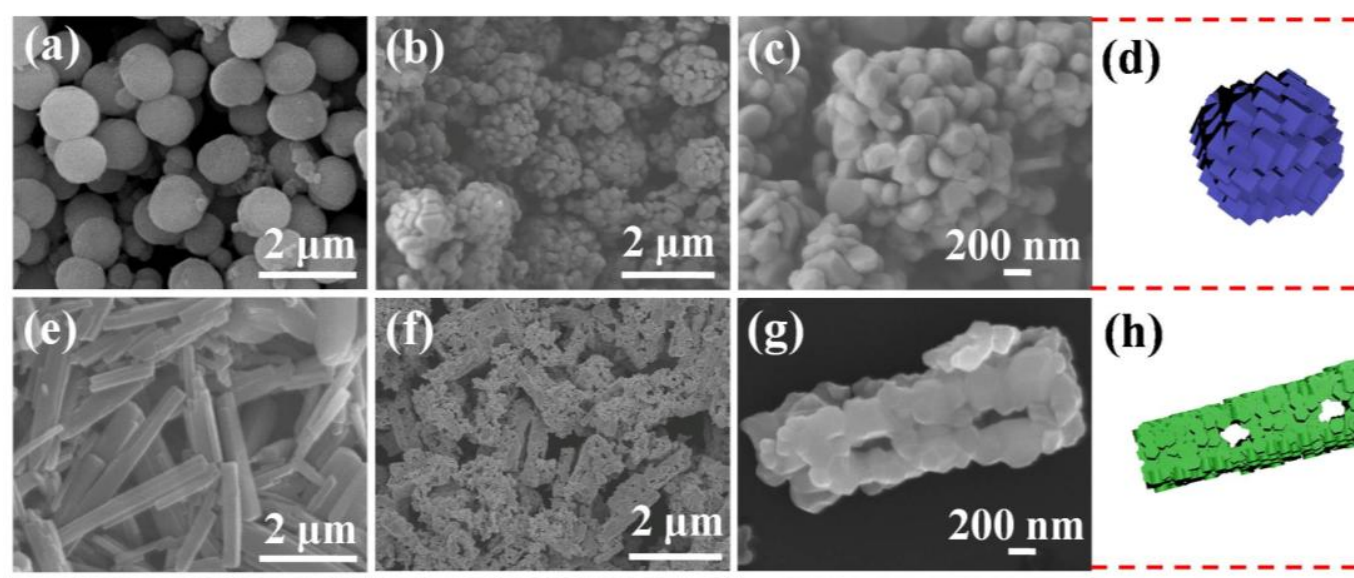

(h)
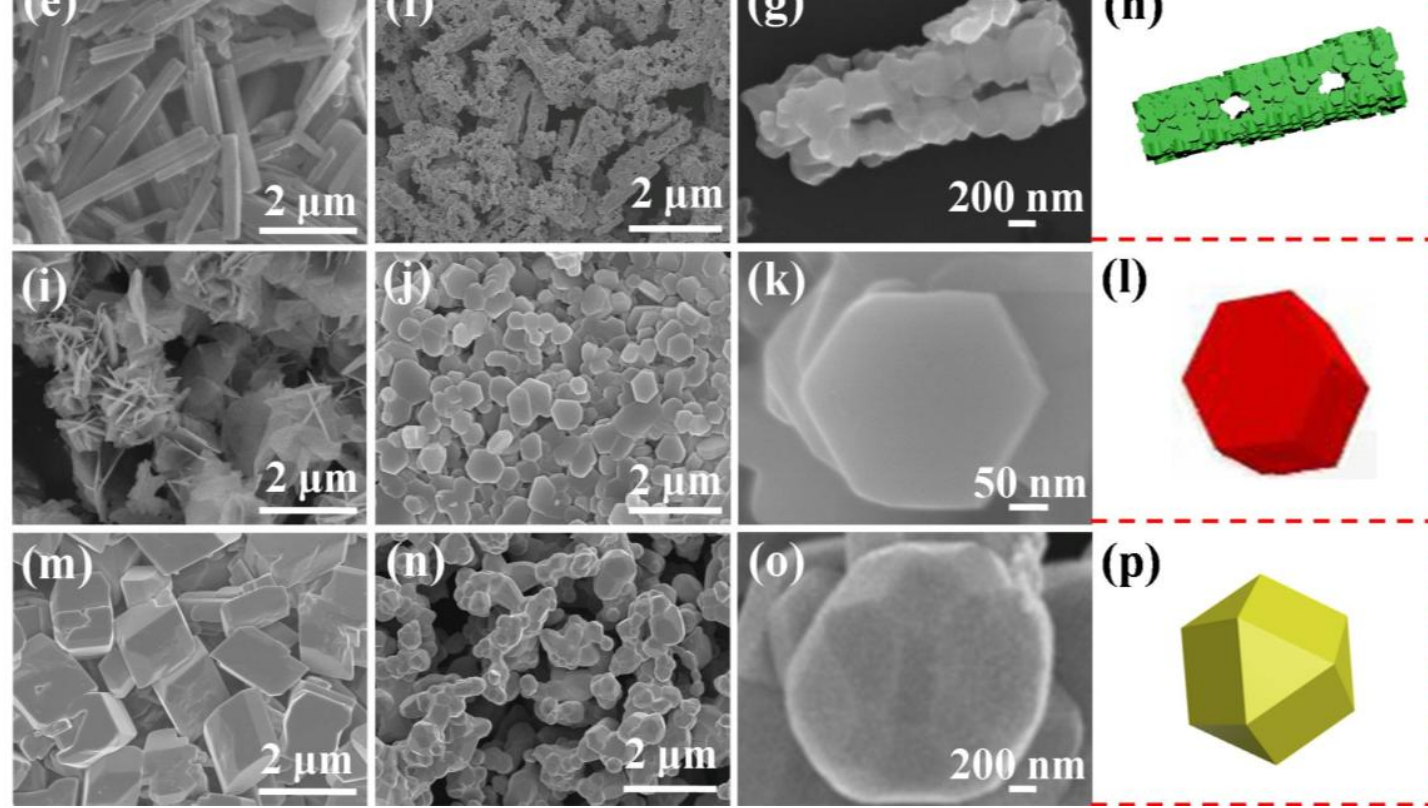

(I)

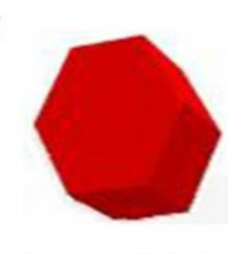

(p)

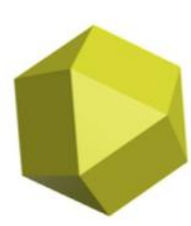

Figure 1 SEM images of the (a) spherical-, (e), (i) plate-, and (m) cube-shaped LLO precursors. SEM images and schematics of LLO microspheres (b-d), microrods (f-h), nanoplates (j-1), and irregular particles (n-p).

and $\mathrm{S} 2 \mathrm{a}-\mathrm{b}$, the microspheres are assembled from plate-like nanoparticles as building blocks and have an average particle size of $200 \mathrm{~nm}$. Figures 1e and f-g show SEM images of the rod-like precursor and product, respectively, prepared by the ethanol/water-based solvothermal method. As shown in Figure 1e, the prepared Li-Ni-Co-Mn- $\mathrm{C}_{2} \mathrm{O}_{4}$ precursor consists entirely of uniform microrods with a diameter 100-200 $\mathrm{nm}$ and length of 2-3 $\mu \mathrm{m}$. After high temperature calcination, the smooth precursor microrods were transformed into porous hierarchical LLO microrods, which consist of a large agglomeration of nanoplates with a size of 100-200 nm (Figures $1 \mathrm{f}-\mathrm{g}$ and S2c-d). The diameter and length of LLO microrods are around 400-500 $\mathrm{nm}$ and 2-3 $\mu \mathrm{m}$, respectively. Figures $1 \mathrm{i}$, and $\mathrm{j}-\mathrm{k}$ present SEM images of the sheet-like precursor and plate-like LLO, respectively, prepared by the co-precipitation method. It is clear that the thicknesses of the synthesized Ni-Co-Mn hydroxide nanosheet 
precursors is only $\sim 10 \mathrm{~nm}$ (Figure 1i). After mixing with lithium salts and being calcined at high temperature, the nanosheet structure changed into nanoplates with a significantly increased thickness $(\sim 30 \mathrm{~nm})$. As revealed in Figures $1 \mathrm{j}$ and $\mathrm{k}$, the smooth LLO nanoplates have a well-defined hexagonal shape with an average edge length of $\sim 150 \mathrm{~nm}$. Figures $1 \mathrm{~m}$ and $\mathrm{n}$-o present SEM images of the cube-like precursor and irregular-shaped LLO, respectively, prepared by the water-based solvothermal method. The as prepared $\mathrm{Li}-\mathrm{Ni}-\mathrm{Co}-\mathrm{Mn}-\mathrm{C}_{2} \mathrm{O}_{4}$ precursor has a cubic shape with sizes of 1-2 $\mu \mathrm{m}$ (Figure $1 \mathrm{~m}$ ). The XRD pattern (Figure S1) of this precursor demonstrates a typical metal oxalate and is very similar with that prepared by the ethanol/water-based solvothermal method (rod-like shape). After calcination, the morphology of the precursor changes completely. The resultant LLO is mainly composed of irregular-shaped particles with diameters of $\sim 1 \mu \mathrm{m}$ (Figure 1n-o). The above results demonstrate that, by using different solvents and synthetic strategies, we synthesized LLO with a range of morphologies, including 3D microspheres, 1D porous microrods, 2D nanoplates, and irregular particles. Schematics of these different morphologies are illustrated in Figures 1d, h, 1, and p, respectively.
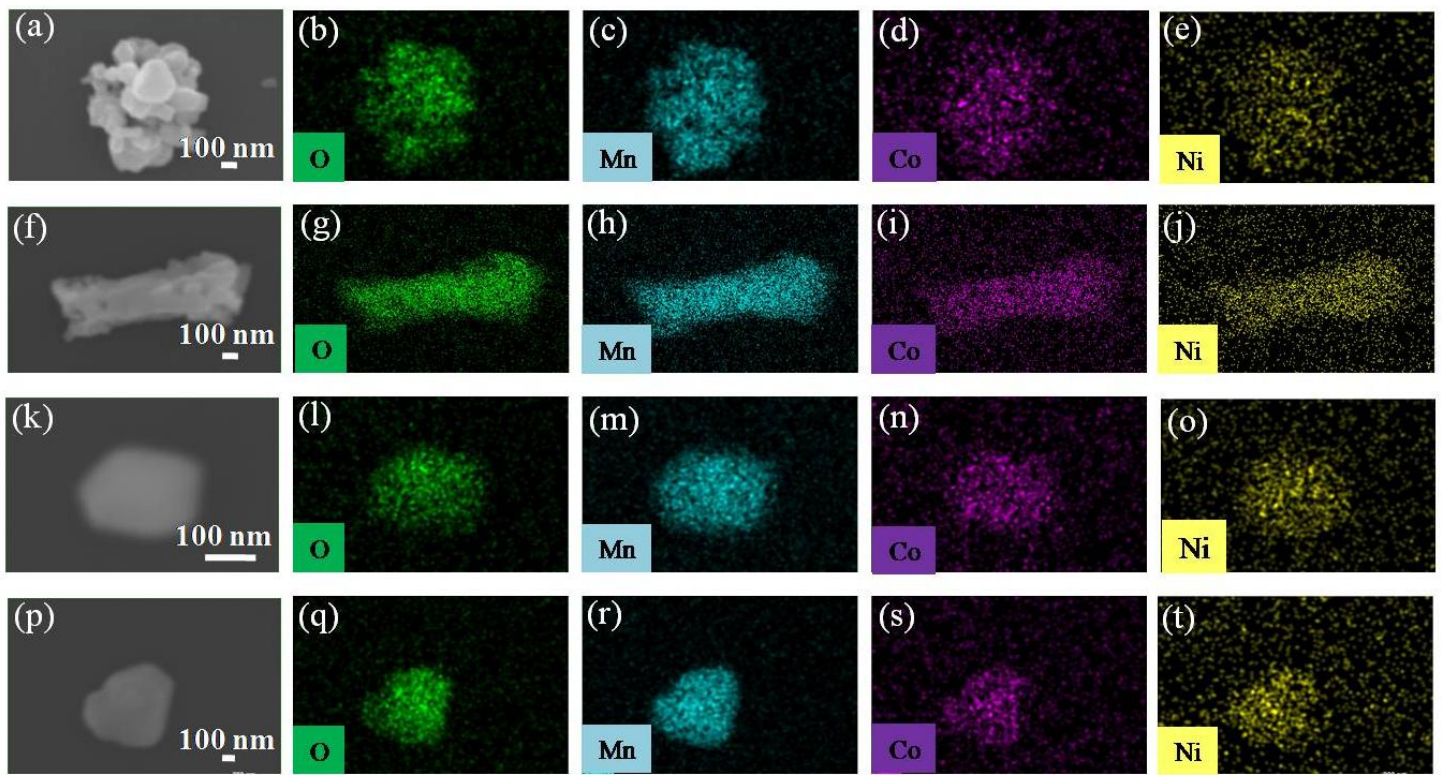

Figure 2 SEM images and elemental mappings of LLO microsphere (a-e), microrod (f-j), nanoplate $(\mathrm{k}-\mathrm{o})$, and irregular particle $(\mathrm{p}-\mathrm{t})$.

The composition and distribution of the different elements in various LLO 
samples were obtained by EDX. The mapping results demonstrate that $\mathrm{Mn}, \mathrm{Co}, \mathrm{Ni}$ and $\mathrm{O}$ are uniformly distributed throughout the LLO microsphere, microrod, nanoplate, and irregular-shaped particle (Figures $2 \mathrm{a}-\mathrm{e}, \mathrm{f}-\mathrm{j}, \mathrm{k}-\mathrm{o}$, and p-t, respectively). EDX spectra (Figures S3a, b, and d) reveal that the atomic ratios of Mn:Co:Ni in all LLO samples except the nanoplate are almost the same, with a feeding ratio of 0.56:0.12:0.12. The molar ratio of the LLO nanoplate made via the co-precipitation method is $0.53: 0.13: 0.14$, which indicates a slightly Mn deficiency in the feeding ratio (Figure S3c). It is possible that the Mn did not completely precipitate during the co-precipitation process because of its larger solubility product than that of $\mathrm{Ni}$ and $\mathrm{Co}$, resulting in the Mn deficiency [18].
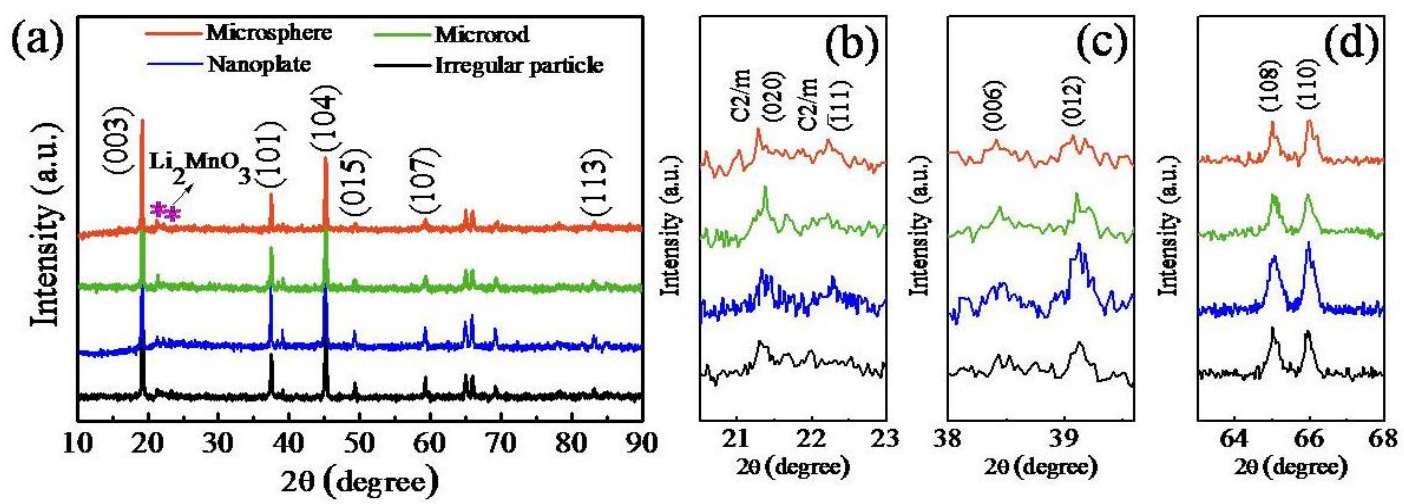

Figure 3 (a) Overall and (b-d) select 2 $\theta$-range XRD patterns of LLO microsphere, microrod, nanoplate, and irregular particle, respectively.

The phase structures of LLO samples with different morphologies were analyzed by XRD. As shown in Figure 3, all four samples show a similar XRD pattern, in which the main peaks can be readily indexed to a hexagonal a-NaFeO ${ }_{2}$ structure with space group $\mathrm{R} \overline{3} \mathrm{~m}$ (Figure 3a). The weak peaks between $20^{\circ}$ and $23^{\circ}$ are consistent with the $\mathrm{LiMn}_{6}$ cation arrangement in the transition metal layer of the $\mathrm{Li}_{2} \mathrm{MnO}_{3}$ phase and can be assigned to its (020) and (111) planes (Figure 3b) [19]. The clear separation of adjacent peaks of (006)/(012) and (108)/(110) indicates the formation of a typical layered structure for all samples (Figures 3c-d) [20]. The intensity ratio of $\mathrm{I}(003) / \mathrm{I}(104)$ has been commonly considered as a measure of the cation mixing 
degree in Li layers [18]. The respective intensity ratios of $\mathrm{I}(003) / \mathrm{I}(104)$ for the LLO microsphere, microrod, nanoplate, and irregular-shaped particle are 1.45, 1.22, 1.51, and 1.44. All these values are larger than 1.2, indicating very low cation mixing degrees in all samples.

The formation processes of LLO samples with different morphologies are illustrated in Figure 4. The morphology and structure of the final product are mainly influenced and determined by the morphology of the precursor. Thus, the formation process of the precursor is discussed here. In general, the morphology of the precursor is highly dependent on the synthesis conditions, solvent used, and synthesis method. In the formation of nanoplates (Figure 4c), the dissolved $\mathrm{Mn}^{2+}, \mathrm{Co}^{2+}$ and $\mathrm{Ni}^{2+}$ ions can form $\left[\mathrm{Mn}-\mathrm{Co}-\mathrm{Ni}-\left(\mathrm{NH}_{4}\right)_{6}\right]^{2+}$ complexes after the coordination reaction with $\mathrm{NH}_{4}{ }^{+}$. The complexes can be precipitated by $\mathrm{OH}^{-}$ions, leading to the formation of $\mathrm{Mn}-\mathrm{Co}-\mathrm{Ni}-(\mathrm{OH})_{2}$ that possesses a hexagonal layered structure with a Mn-Co-Ni layer being sandwiched between two O layers [21]. Thus, the LLO precursor Mn-Co-Ni- $(\mathrm{OH})_{2}$ tends to grow in a hexagonal shape due to its intrinsic lamellar structure.

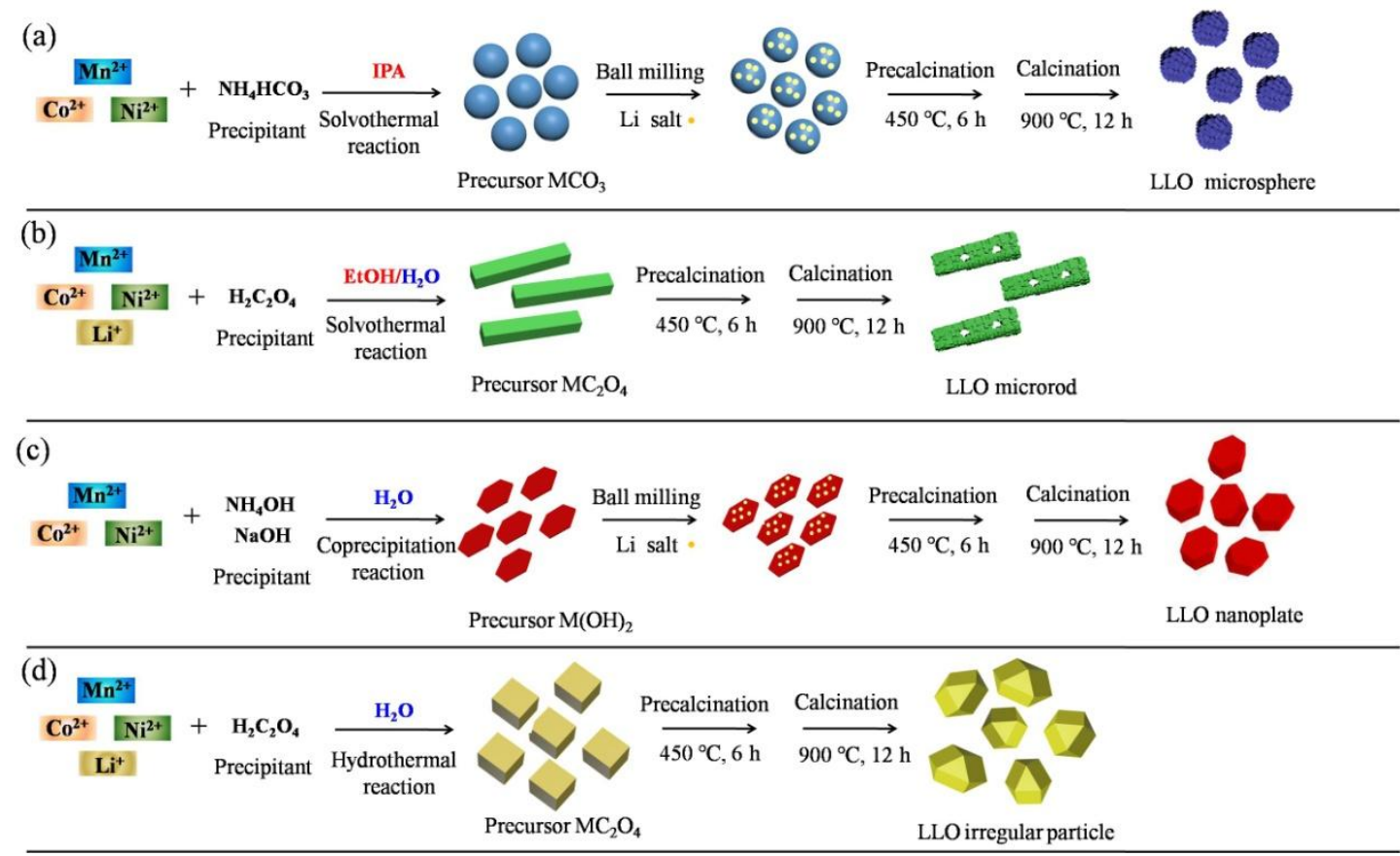

Figure 4 Schematic illustration of the formation processes of the LLO microsphere (a), microrod (b), nanoplate (c), and irregular particle (d). 
Under the mild co-precipitation condition using $\mathrm{NaOH}-\mathrm{NH}_{3} \cdot \mathrm{H}_{2} \mathrm{O}$, the crystallization and growth of LLO precursor are mainly determined by the intrinsic crystal structure. When the types of feeding materials and reaction solvents are changed, the initial nucleation and preferred orientation of the crystals can be significantly affected [22]. In addition, the growth of the crystals can also be affected by the reaction temperature and pressure. In the solvothermal process (Figures $4 a, b$, and d), spherical-, rod-, and cube-like LLO precursors were produced when isopropanol, ethanol/water (1:1), and pure water were used as the solvent, respectively. This result suggests that solvent plays a crucial role in the formation of different morphologies of precursors. Solvents with different polarities have different chelating behaviors with metal cations causing various crystal growth pathways [23]. Because the polarity of isopropanol is much lower than that of ethanol, the solid interface-solvent interaction should be also weaker, leading to less anisotropic growth and formation of spherical morphology. Ethanol has high polarity and a hydroxyl group, which can preferentially adsorb on specific crystallite faces. When solvent contains a high concentration of ethanol, the growth along uncapped faces is enhanced, easily resulting in rod-like morphology. Therefore, long rod-like precursors were formed in the ethanol/water solvent, while short cube-like precursors were obtained in the water solvent.

To determine the influence of structure on the electrochemical performance of LLO, electrochemical tests were carried out at $0.2-8 \mathrm{C}\left(1 \mathrm{C}=200 \mathrm{~mA} \mathrm{~g}^{-1}\right)$ and room temperature $\left(22{ }^{\circ} \mathrm{C}\right)$ in the voltage range of $2.0-4.8 \mathrm{~V}$. Figure 5a shows the initial charge/discharge voltage profiles of LLO samples with different structures at a $0.5 \mathrm{C}$ rate. During the initial charge, all samples exhibit two distinguishable stages. One is a smooth sloping region below $4.5 \mathrm{~V}$ corresponding to $\mathrm{Li}^{+}$deintercalation from the $\mathrm{LiMn}_{0.4} \mathrm{Ni}_{0.3} \mathrm{Co}_{0.3} \mathrm{O}_{2}$ phase (region I). The other is a long plateau region at around 4.5 $\mathrm{V}$, corresponding to the extraction of $\mathrm{Li}^{+}$from the $\mathrm{Li}_{2} \mathrm{MnO}_{3}$ phase and structural rearrangement (region II). Obviously, the voltage plateau for the LLO microrods around $4.5 \mathrm{~V}$ is longer than that of all other samples, which means more $\mathrm{Li}_{2} \mathrm{MnO}_{3}$ phase is activated in the LLO microrods. The charge capacity for the LLO microrods 

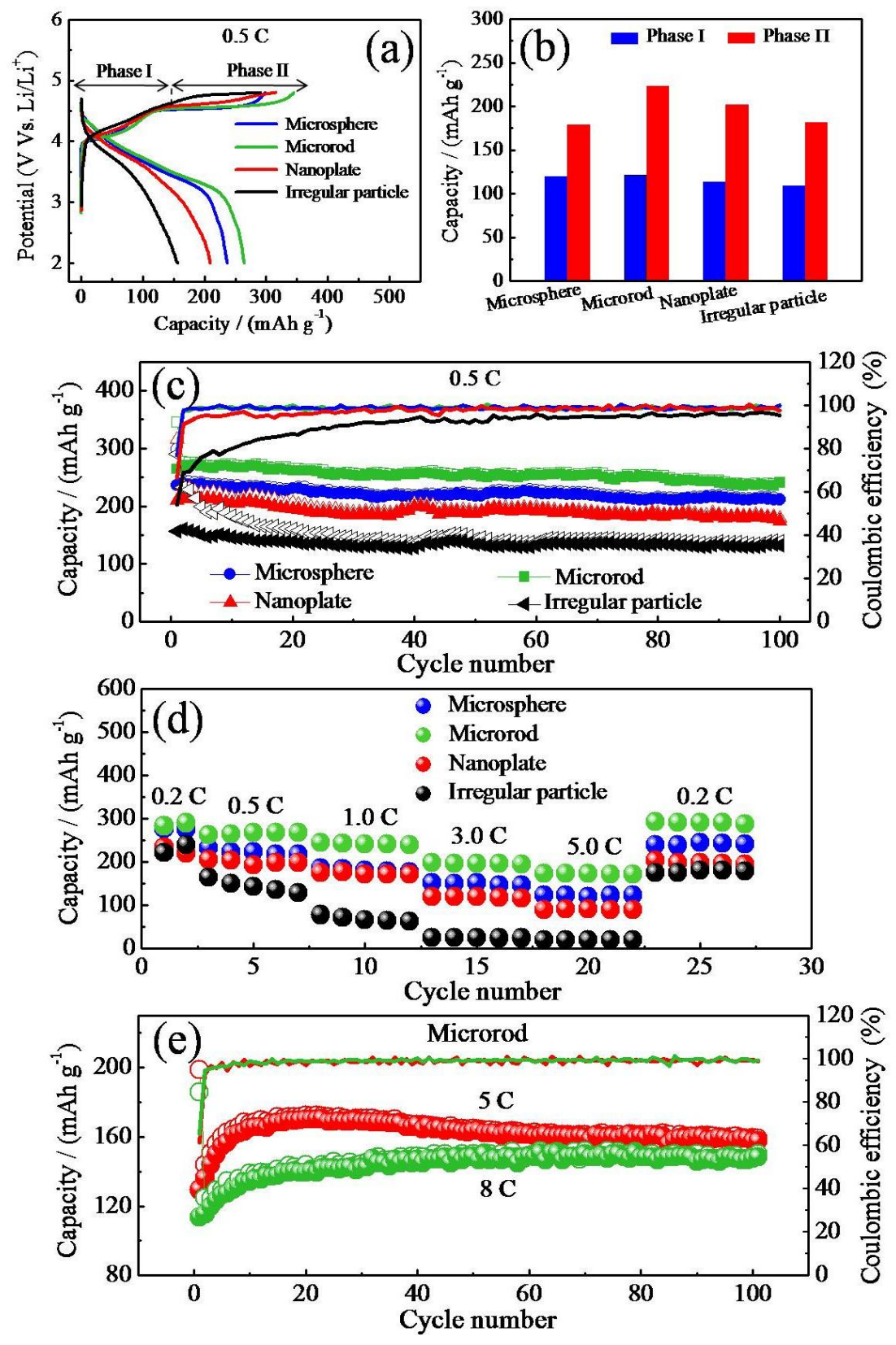

Figure 5 Electrochemical performance of LLO microsphere, microrod, nanoplate, and irregular particle cathode materials in LIBs: (a) initial charge/discharge curves at 0.5 $\mathrm{C}$ rate within voltage range of 0.01-3.0 V; (b) histogram of initial charge capacities attributed by $\mathrm{LiMn}_{0.4} \mathrm{Ni}_{0.3} \mathrm{Co}_{0.3} \mathrm{O}_{2}$ and $\mathrm{Li}_{2} \mathrm{MnO}_{3}$ phases; (c) cycling performance and corresponding coulombic efficiency at $0.5 \mathrm{C}$ rate for 100 cycles; (d) rate performance at various current rates from $0.2 \mathrm{C}$ to $5 \mathrm{C}$; (e) cycling performance and corresponding coulombic efficiency of LLO microrods at high rates of $5 \mathrm{C}$ and $8 \mathrm{C} .(1 \mathrm{C}=200 \mathrm{~mA}$ $\mathrm{g}^{-1}$.)

contributed from the voltage above $4.5 \mathrm{~V}$ is $223.2 \mathrm{mAh} \mathrm{g}^{-1}$ (Figure $5 \mathrm{~b}$ ), which is higher than that for the microspheres (178.6 $\left.\mathrm{mAh} \mathrm{g}^{-1}\right)$, nanoplates $\left(202.1 \mathrm{mAh} \mathrm{g}^{-1}\right)$, and irregular particles (181.1 $\left.\mathrm{mAh}^{-1}\right)$. Since the contributions from the 
$\mathrm{LiMn}_{0.4} \mathrm{Ni}_{0.3} \mathrm{Co}_{0.3} \mathrm{O}_{2}$ phase for all the samples are almost the same, a higher contribution from the $\mathrm{Li}_{2} \mathrm{MnO}_{3}$ phase results in a higher overall initial discharge capacity (Figure 5b). The initial discharge capacity for the LLO microrods is 264.6 $\mathrm{mAh} \mathrm{g}^{-1}$, which is significantly higher than those of $236.7,209.8$, and $156.3 \mathrm{mAh} \mathrm{g}^{-1}$ for the LLO microspheres, nanoplates, and irregular particles, respectively. The high initial charge/discharge capacities for the LLO microrods samples might be associated with their highly porous structure.

Figure $5 \mathrm{c}$ compares the cycling performance of various LLO samples at $0.5 \mathrm{C}$. Both LLO microrods and microspheres show very stable cycle performance. After 100 cycles, the LLO microrods and microspheres can still deliver high discharge capacities of 241.1 and $211 \mathrm{mAh} \mathrm{g}^{-1}$, respectively. In contrast, the discharge capacities of the nanoplates and irregular particles are only 174.8 and $126.5 \mathrm{mAh} \mathrm{g}^{-1}$, respectively. The capacity retention rates achieved at the end of 100 cycles for these samples decrease in the following order: microrods $(91.1 \%)>$ microspheres $(89.1 \%)>$ nanoplates $(83.3 \%)>$ irregular particles $(80.9 \%)$. Microrods and microspheres exhibit higher cycling stability than other morphologies, because they benefit from their robust secondary microstructures.

One of the critical issues of LLO is the voltage fading during cycling. Figure S4 compares the discharge curves of the $2^{\text {nd }}, 25^{\text {th }}, 50^{\text {th }}$, and $100^{\text {th }}$ cycles at $0.5 \mathrm{C}$ for different LLO samples. Clearly, voltage fading exists in all samples mainly due to the continuous structural evolution from layered to spinel-like phase [24,25]. The voltage drops of nanoplates and irregular particles after 100 cycles are much larger than that of microspheres and microrods, suggesting that secondary particles are beneficial for alleviating voltage fading.

Figure $5 \mathrm{~d}$ shows the rate performance of the different LLO samples at rates from $0.2 \mathrm{C}$ to $5 \mathrm{C}$. At all rates, the LLO microrods perform better than other samples. At the highest rate of $5 \mathrm{C}$, the discharge capacity for the microrods can still reach 173.6 $\mathrm{mAh} \mathrm{g}^{-1}$, about $61.4 \%$ of the discharge capacity at $0.2 \mathrm{C}$. For LLO microspheres and nanoplates, the discharge capacities at $5 \mathrm{C}$ are only 123.3 and $90.5 \mathrm{mAh} \mathrm{g}^{-1}$, respectively, which are much lower than that for the microrods. For the irregular 
particles, the discharge capacity is only $20 \mathrm{mAh} \mathrm{g}^{-1}$ at the $5 \mathrm{C}$ rate. When the rate was abruptly switched back to $0.2 \mathrm{C}$, the microrods still attained a discharge capacity of $293 \mathrm{mAh} \mathrm{g}^{-1}$, indicating no capacity loss. However, when the rate was returned to 0.2 $\mathrm{C}$, the microspheres, nanoplates, and irregular particles all exhibited a large capacity loss. The discharge capacities for the microrods at different rates are among the best results ever achieved for Li-rich layered cathodes [26-30]. The super rate capability of LLO microrods might be related to its porous hierarchical structure, which results in many porous channels for electrolyte transport. In addition, the interconnected primary nanoparticles ensure rapid $\mathrm{Li}^{+}$intercalation/deintercalation.

Figure 5e presents the cycling performance for LLO microrods at high rates of 5 $\mathrm{C}$ and $8 \mathrm{C}$. After initial activation, the discharge capacities increased to 170.3 and $150.6 \mathrm{mAh} \mathrm{g}^{-1}$ at $5 \mathrm{C}$ and $8 \mathrm{C}$, respectively. After 100 cycles, the discharge capacities remained at 157.5 and $148.1 \mathrm{mAh} \mathrm{g}^{-1}$, respectively, which are $92.4 \%$ and $98.3 \%$ of their maximum capacities. Such high rate performance and cycling stability at high charge/discharge rates are much better than those of previously reported LLO cathodes [30-34].

To gain further insight into the electrochemical behavior of different LLO structures, CV and EIS measurements were conducted. Figures 6a, c, e, and g show the CV curves for the LLO microrods, microspheres, nanoplates, and irregular particles, respectively, recorded at various scan rates from 0.2 to $0.7 \mathrm{mV} \mathrm{s}^{-1}$ in the voltage range of 2-4.8 V. In a typical CV, two oxidation peaks appear at 4.25 and 4.75 $\mathrm{V}$ in the first anodic process. The peak at $4.25 \mathrm{~V}$ is ascribed to the oxidation of $\mathrm{Ni}^{2+} / \mathrm{Ni}^{4+}$ and $\mathrm{Co}^{3+} / \mathrm{Co}^{4+}[35]$. The latter is due to the irreversible electrochemical activation of $\mathrm{Li}_{2} \mathrm{MnO}_{3}$ phase forming $\mathrm{MnO}_{2}$ [31]. In subsequent cycles, the anodic oxidation peak at around $4.75 \mathrm{~V}$ vanishes, and a new peak appears at $\sim 4.0 \mathrm{~V}$, corresponding to the oxidation of transition metal ions [30]. In the cathodic process, the reduction reactions of $\mathrm{Co}^{4+} / \mathrm{Co}^{3+}, \mathrm{Ni}^{4+} / \mathrm{Ni}^{2+}$, and $\mathrm{Mn}^{4+} / \mathrm{Mn}^{3+}$ are reflected from peaks at $4.22,3.73$, and $3.15 \mathrm{~V}$, respectively. With increasing scanning rate, all peak currents increase. In a diffusion-controlled process, the peak currents at a certain potential are proportional to the square root of the scanning rate [36]. In our studies, 

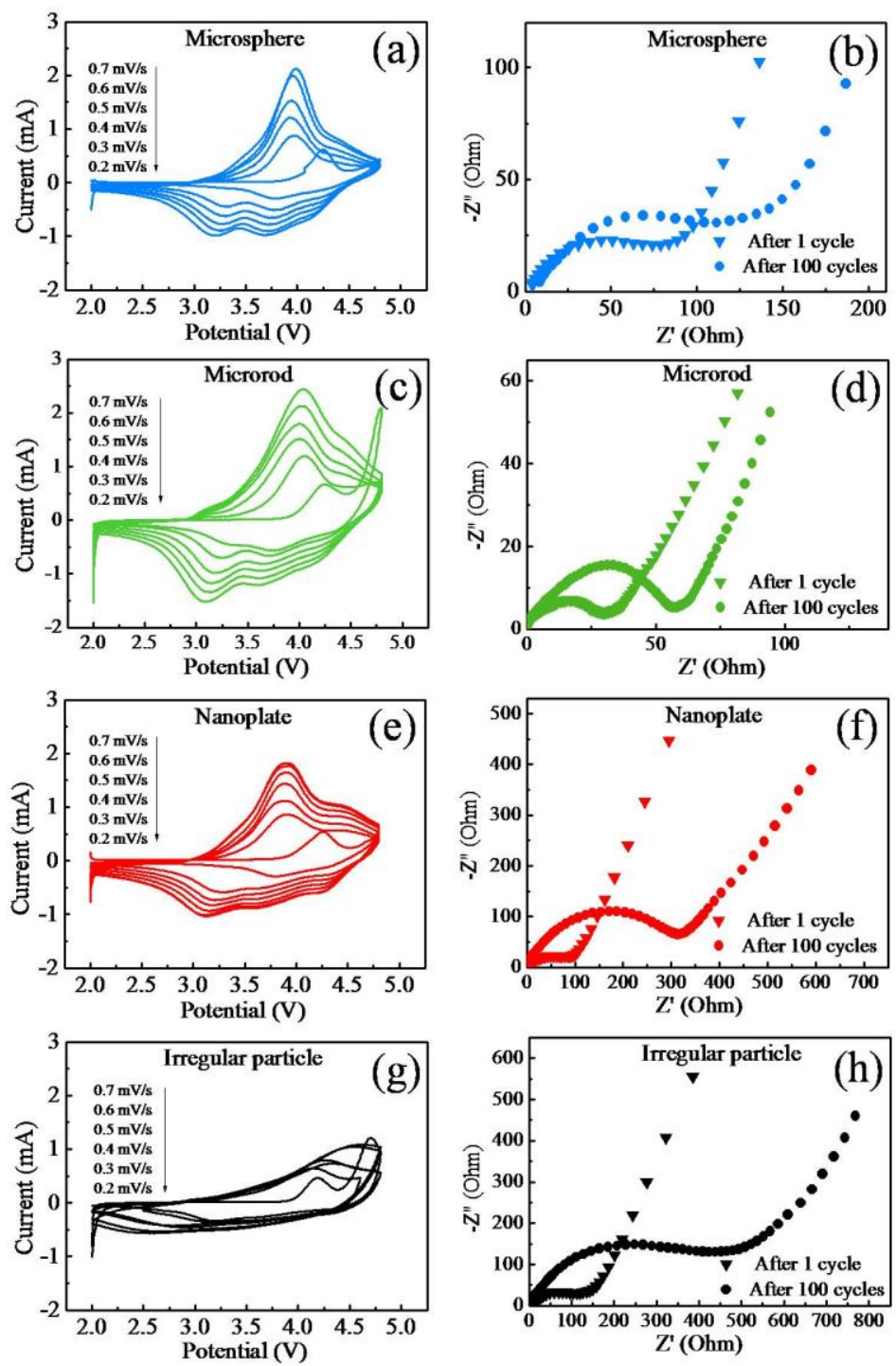

Figure $6 \mathrm{CV}$ curves of LLO microspheres (a), microrods (c), nanoplates (e), and irregular particles (g). EIS spectra of LLO microspheres (b), microrods (d), nanoplates (f), and irregular particles (h) after 1 st and 100th cycles at $0.5 \mathrm{C}$ rate.

the diffusion coefficient of $\mathrm{Li}^{+}$in LLO samples can be analyzed by the Randles-Sevick equation [37]:

$$
i_{p}=2.69 \times 10^{5} n^{3 / 2} A D_{L i}^{1 / 2} C_{L i} v^{1 / 2}
$$

where $i_{p}$ is the peak current, $n$ is the number of the electrons transferred, $A$ is the surface area of the electrode, $v$ is the scan rate, and $D_{L i}$ and $C_{L i}$ are the diffusion coefficient and concentration of $\mathrm{Li}^{+}$, respectively. The intercalation $D_{L i}$ calculated from the cathodic peak at $3.15 \mathrm{~V}$ (discharge process in Figure S5) increases in the order of irregular particles $\left(5.525 \times 10^{-11} \mathrm{~cm}^{2} \mathrm{~s}^{-1}\right)<$ nanoplates $\left(1.896 \times 10^{-10} \mathrm{~cm}^{2} \mathrm{~s}^{-1}\right)<$ 
microspheres $\left(3.408 \times 10^{-9} \mathrm{~cm}^{2} \mathrm{~s}^{-1}\right)<$ microrods $\left(6.745 \times 10^{-9} \mathrm{~cm}^{2} \mathrm{~s}^{-1}\right)$. The deintercalation $D_{L i}$ calculated from the anodic peak at $4.0 \mathrm{~V}$ (charge process in Figure S5) also increases in the order of irregular particles $\left(2.249 \times 10^{-10} \mathrm{~cm}^{2} \mathrm{~s}^{-1}\right)<$ nanoplates $\left(9.481 \times 10^{-10} \mathrm{~cm}^{2} \mathrm{~s}^{-1}\right)<$ microspheres $\left(1.614 \times 10^{-9} \mathrm{~cm}^{2} \mathrm{~s}^{-1}\right)<\operatorname{microrods}\left(1.723 \times 10^{-9}\right.$ $\mathrm{cm}^{2} \mathrm{~s}^{-1}$ ). The values of $D_{L i}$ in both the intercalation/deintercalation processes were larger for the porous microrods as compared to other samples. Not surprisingly, the porous LLO microrods favor faster $\mathrm{Li}^{+}$intercalation/deintercalation kinetics.

The Nyquist plots for the LLO samples derived from the EIS measurements after the 1st and 100th cycles are shown in Figures 6b, d, f, and h for the LLO microrods, microspheres, nanoplates, and irregular particles, respectively. All the spectra exhibit a semicircle at high-medium frequencies corresponding to the charge transfer resistance $\left(R_{\mathrm{ct}}\right)$. The inclined line in the low-frequency range is considered as the Warburg impedance, corresponding to the $\mathrm{Li}^{+}$diffusion inside the electrode material [38]. Note that rather different behavior in $R_{\mathrm{ct}}$ is observed for LLO samples. Compared with LLO nanoplates and irregular particles, LLO microrods and microspheres demonstrate smaller change in $R_{\mathrm{ct}}$ and much lower $R_{\mathrm{ct}}$ after 100 cycles (Table S1). The robust micro-sized architecture and high structural stability of LLO microrods and microspheres account for the smaller change in $R_{c t}$ and lower $R_{c t}$ after cycling.

\section{Discussion}

The electrochemical tests clearly illustrated that the performance of the different LLO structures follows the order: microrods $>$ microspheres $>$ nanoplates $>$ irregular particles. The distinct difference in the performance of the four LLO samples can be understood from their morphological and structural features.

Microrods have a porous structure and 1D shape. The remarkable electrochemical performance of LLO microrods may result from the synergistic effect of the porous structure, 1D shape, nanoscale size, and robust microstructure. First, the porous structure can provide large contact areas between the electrolyte and solid active material, more open channels for ion transfer, and more electrochemical active 
sites. These factors improve the specific capacity and reaction kinetics. Second, the 1D shape can provide a short distance for ion diffusion along the confined radial dimension, facilitating $\mathrm{Li}^{+}$diffusion. Third, the nanoscale size of the primary particle decreases the energy barrier for $\mathrm{Li}^{+}$transport, further improving the $\mathrm{Li}^{+}$diffusion. Additionally, the robust secondary microstructure could enhance the structural integrity upon cycling and reduce the undesired side reactions, leading to superior cycling stability (Figure S6). In sum, the enhanced reaction kinetics, transport rate, and structural stability significantly improve the electrochemical properties of LLO microrods. Thus, even though microrod has the lowest intensity ratio of $\mathrm{I}(003) / \mathrm{I}(104)$ among all samples, it exhibits the best performance.

In comparison with the nanoplates and irregular particles, the LLO microspheres have a robust micron-scale secondary architecture, which is critical for a high capacity and stability. The spherical microstructure is stable enough to respond and tolerate repeated charge and discharge (Figure S6), and alleviate the side reactions between active material and electrolyte, leading to the attractive structural stability and good cycle life.

\section{Conclusion}

In summary, the relationship between the morphologies and electrochemical properties of LLO are investigated and discussed here. Microspheres, microrods, nanoplates, and irregular particles are successfully synthesized by solvothermal and co-precipitation methods. The polarity of the solvents is found to play an important role in controlling the morphologies of the precursors. The solvents with higher polarities tend to result in precursors with long rod-like morphology. The electrochemical performance in lithium-ion batteries of LLO samples is strongly dependent on their morphologies and structures. LLO microrods show excellent performance and outstanding cycling stability at high rates, which is much superior to other structures studied. The outstanding electrode performance of microrods could be attributed to the unique 1D porous hierarchical structure, which favors fast $\mathrm{Li}^{+}$ transport kinetics and high structural stability during reversible electrochemical 
processes. This work offers fundamental insights into the structure-property relationships of Li-rich layered oxides, which will promote the rational design and synthesis of active materials for advanced batteries.

\section{Acknowledgements}

The authors acknowledge the support from the Innovation and Technology Fund (ITS/161/16FP) of the Hong Kong Special Administrative Region, a startup fund from the Hong Kong University of Science and Technology, and NSFC grant (21621091). This work was also supported by the U.S. Department of Energy under Contract DE-AC0206CH11357 from the Vehicle Technologies Office, Department of Energy, Office of Energy Efficiency and Renewable Energy (EERE).

\section{References}

[1] J.H. Wang, Y.K. Yamada, K. Sodeyama, C.H. Chiang, Y. Tateyama, A. Yamada, Nat. Commun. 7 (2015) 12032.

[2] J. Lu, C. Zhan, T.P. Wu, J.G. Wen, Y. Lei, A.J. Kropf, H.M. Wu, D.J. Miller, J.W. Elam, Y.K. Sun, X.P. Qiu, K. Amine, Nat. Commun. 5 (2014) 5693.

[3] B. Qiu, M.H. Zhang, L.J. Wu, J. Wang, Y.G. Xia, D.N. Qian, H.D. Liu, S. Hy, Y. Chen, K. An, Y.M. Zhu, Z.P. Liu, Y.S. Meng, Nat. Commun. 7 (2016) 12108.

[4] J.M. Zheng, M. Gu, J. Xiao, P.J. Zuo, C.M. Wang, J.G. Zhang, Nano Lett. 13 (2013) 3824-3830.

[5] D.P. Wang, I. Belharouak, G.W. Zhou, K. Amine, Adv. Funct. Mater. 23 (2013) 1070-1075.

[6] F. Wu, N. Li, Y.F. Su, H.F. Shou, L.Y. Bao, W. Yang, L.J. Zhang, R. An, S. Chen, Adv. Mater. 25 (2013) 3722-3726.

[7] Y.K. Sun, M.J. Lee, C.S. Yoon, J. Hassoun, K. Amine, B. Scrosati, Adv. Mater. 24 (2012) 1192-1196.

[8] J. Zhang, Q.W. Lu, J.H. Fang, J.L. Wang, J. Yang, Y. NuLi, ACS Appl. Mater. Interfaces 6 (2014) 17965-17973.

[9] Y.Q. Wang, Z.Z. Yang, Y.M. Qian, L. Gu, H.S. Zhou, Adv. Mater. 27 (2015) 3915-3920.

[10] T.F. Yi, Y.M. Li, S.Y. Yang, Y.R. Zhu, Y. Xie, ACS Appl. Mater. Interfaces 8 (2016) 32349-32359.

[11] J.L. Shi, J.N. Zhang, M. He, X.D. Zhang, Y.X. Yin, H. Li, Y.G. Guo, L. Gu, L.J. Wan, ACS Appl. Mater. Interfaces 8 (2016) 20138-20146.

[12] C.H. Zhao, X.X. Wang, X.R. Liu, H. Zhang, Q. Shen, ACS Appl. Mater. Interfaces 6 (2014) 2386-2392. 
[13] G.Z. Wei, X. Lu, F.S. Ke, L. Huang, J.T. Li, Z.X. Wang, Z.Y. Zhou, S.G. Sun, Adv. Mater. 22 (2010) 4364-4367.

[14] J. Fu, C.J. DeSantis, R.G. Weiner, S.E. Skrabalak, Chem. Mater. 27 (2015) 1863-1868.

[15] F. Fu, J.Y. Tang, Y.Z. Yao, M.H. Shao, ACS Appl. Mater. Interfaces 8 (2016) 25654-25659.

[16] L. Chen, Y.F. Su, S. Chen, N. Li, L.Y. Bao, W.K. Li, Z. Wang, M. Wang, F. Wu, Adv. Mater. 26 (2014) 6756-6760.

[17] S. Kuppan, A.K. Shukla, D. Membreno, D. Nordlund, G.Y. Chen, Adv. Energy Mater. 1602010 (2017).

[18] F. Fu, Q. Wang, Y.P. Deng, C.H. Shen, X.X. Peng, L. Huang, S.G. Sun, J. Mater. Chem. A 3 (2015) 5197-5203.

[19] C. Liu, Z.Y. Wang, C.S. Shi, E.Z. Liu, C.N. He, N.Q. Zhao, ACS Appl. Mater. Interfaces 6 (2014) 8363-8368.

[20] F. Fu, G.L. Xu, Q. Wang, Y.P. Deng, X. Li, J.T. Li, L. Huang, S.G. Sun, J. Mater. Chem. A, 1 (2013) 3860-3864.

[21] H.Z. Zhang, Q.Q. Qiao, G.R. Li, S.H. Ye, X.P. Gao, J. Mater. Chem. 22 (2012) 13104-13109.

[22] Y.K. Sun, S.T. Myung, M.H. Kim, J. Prakash, K. Amine, J. Am. Chem. Soc. 127 (2015) 13411-13418.

[23] F.H. Zheng, C.H. Yang, X.H. Xiong, J.W. Xiong, R.Z. Hu, Y. Chen, M.L. Liu, Angew. Chem. Int. Ed. 54 (2015) 13058-13062.

[24] J.M. Zheng, P.H. Xu, M. Gu, J. Xiao, N.D. Browning, P.F. Yan, C.M. Wang, J.G. Zhang, Chem. Mater. 27 (2015) 1381-1390.

[25] J.M. Zheng, S.J. Myeong, W. Cho, P.F. Yan, J. Xiao, C.M. Wang, J. Cho, J.G. Zhang, Adv. Energy Mater. 7 (2017) 1601284.

[26] G. Ma, S. Li, W.X. Zhang, Z.H. Yang, S.L. Liu, X.M. Fan, F. Chen, Angew. Chem. Int. Ed. 55 (2016) 3667-3671.

[27] H. Kim, M.G. Kim, H.Y. Jeong, H. Nam, J. Cho, Nano Lett. 15 (2015) 2111-2119.

[28] L.J. Zhang, N. Li, B.R. Wu, H.L. Xu, L. Wang, X.Q. Yang, F. Wu, Nano Lett. 15 (2015) 656-661.

[29] F. Wu, N. Li, Y.F. Su, L.J. Zhang, L.Y. Bao, J. Wang, L. Chen, Y. Zheng, L.Q. Dai, J.Y. Peng, S. Chen, Nano Lett. 14 (2014) 3550-3555.

[30] Y. Li, C. Wu, Y. Bai, L. Liu, H. Wang, F. Wu, N. Zhang, Y.F. Zou, ACS Appl. Mater. Interfaces 8 (2016) 18832-18840.

[31] X.L. Yuan, Q.J. Xu, C. Wang, X.N. Liu, H.M. Liu, Y.Y. Xia, J. Power Sources 279 (2015) 157-164.

[32] M.Y. Hou, S.S. Guo, J.L. Liu, J. Yang, Y.G. Wang, C.X. Wang, Y.Y. Xia, J. Power Sources 287 (2015) 370-376.

[33] J. Zheng, S.N. Deng, Z.C. Shi, H.J. Xu, H. Xu, Y.F. Deng, Z. Zhang, G.H. Chen, J. Power Sources 221 (2013) 108-113.

[34] S.J. Shi, J.P. Tu, Y.Y. Tang, Y.X. Yu, Y.Q. Zhang, X.L. Wang, C.D. Gu, J. Power Sources 228 (2013) 14-23. 
[35] Y.D. Zhang, Y. Li, X.Q. Niu, D.H. Wang, D. Zhou, X.L. Wang, C.D. Gu, J.P. Tu, J. Mater. Chem. A 3 (2015) 14291-14297.

[36] F.Y. Cheng, H.B. Wang, Z.Q. Zhu, Y. Wang, T.R. Zhang, Z.L. Tao, J. Chen, Energy Environ. Sci. 4 (2011) 3668-3675.

[37] D.W. Su, A. McDonagh, S.Z. Qiao, G.X. Wang, Adv. Mater. 29 (2017) 1604007.

[38] Y. Shi, J.Z. Wang, S.L. Chou, D. Wexler, H.J. Li, K. Ozawa, H.K. Liu, Y.P. Wu, Nano Lett. 13 (2013) 4715-4720.

\section{Vitae}

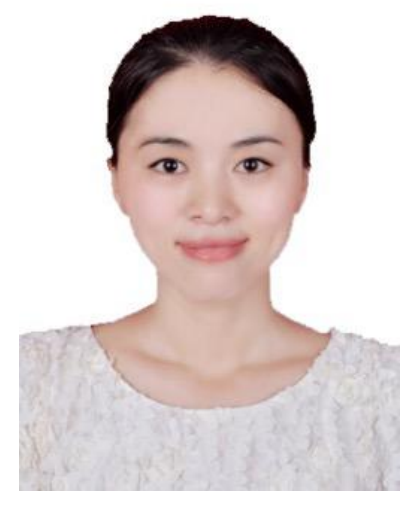

Fang Fu is currently a postdoctoral fellow at the Hong Kong University of Science and Technology in Prof. Minhua Shao's group. She received her Ph.D. degree in electrochemistry from Xiamen University in 2013. Her research interests mainly focus on the design and development of advanced structured materials for high performance $\mathrm{Li}$-ion and $\mathrm{Na}$-ion batteries.

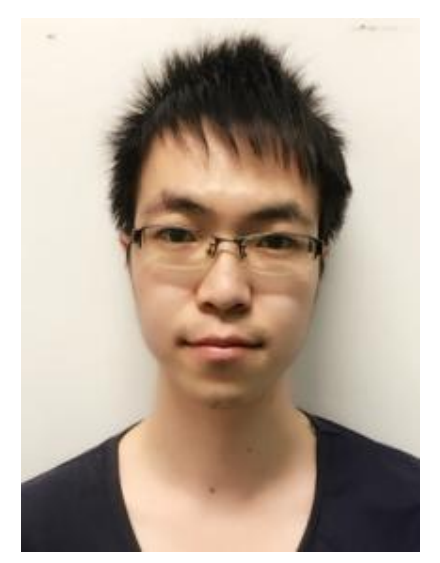

Yuze Yao received his BS degree in materials science and engineering from 
University of Science and Technology Beijing in 2015. He is now a Mphil student at the Hong Kong University of Science and Technology under the supervision of Professor Minhua Shao. His main research interests are advanced materials for Li-ion battery.

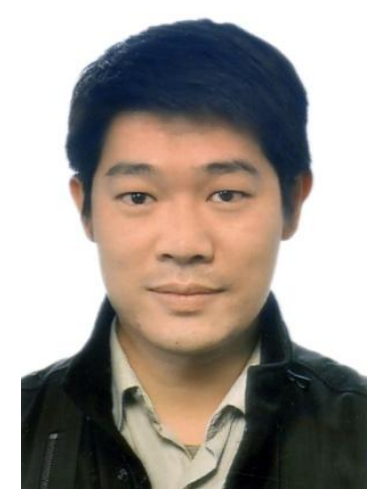

Haiyan Wang, is an associate Professor in College of Chemistry and Chemical Engineering at Central South University. He has published over 70 refereed papers. His current research interests are focused mainly on the new energy materials and devices, including aqueous/non-aqueous $\mathrm{Li}(\mathrm{Na})$ ion batteries and metal-air batteries.

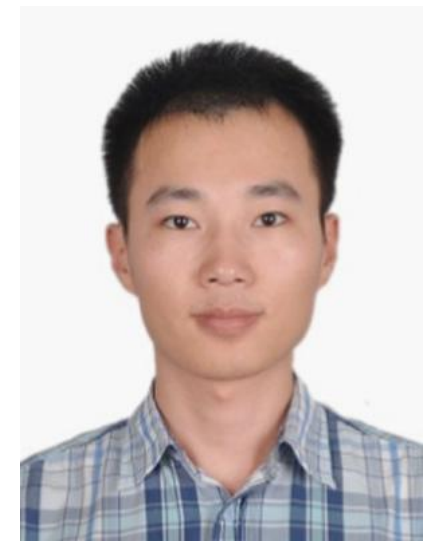

Gui-Liang Xu received his Bachelor in July 2009 and Ph. D. degree in June 2014 from Department of Chemistry of Xiamen University. He is now a post-doctoral fellow at Argonne national laboratory. He mainly focuses on the research of advanced battery materials and their study by in-situ synchrotron X-ray techniques. 


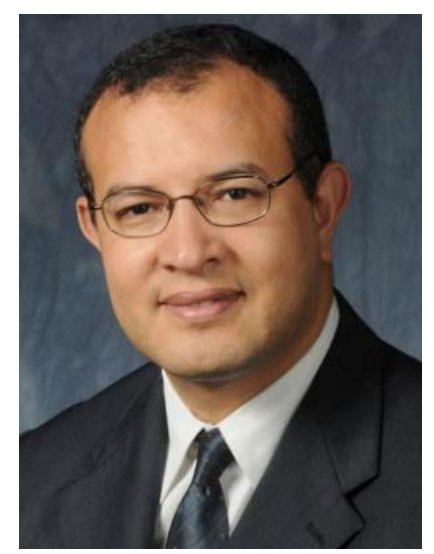

Dr. Khalil Amine is a Distinguished Fellow and the Manager of the Advanced Battery Technology programs at Argonne National Laboratory, where he is responsible for directing the research and development of advanced materials and battery systems for HEV, PHEV, EV, satellite, military and medical applications. Dr. Amine currently serves a member of the U.S. National Research Consul on battery related technologies. Among his many awards, Dr. Khalil is a 2003 recipient of Scientific America's Top Worldwide Research 50 Research Award, a 2009 recipient of the US Federal Laboratory Award for Excellence in Technology Transfer, and is the five-time recipient of the R \& D 100 Award, which is considered as the Oscar of technology and innovation. In addition, he was recently awarded the ECS battery technology award and the international battery association award. Dr. Amine holds or has filed over 130 patents and patent applications and has over 280 publications. From 1998-2008, Dr. Amine was the most cited scientist in the world in the field of battery technology. 


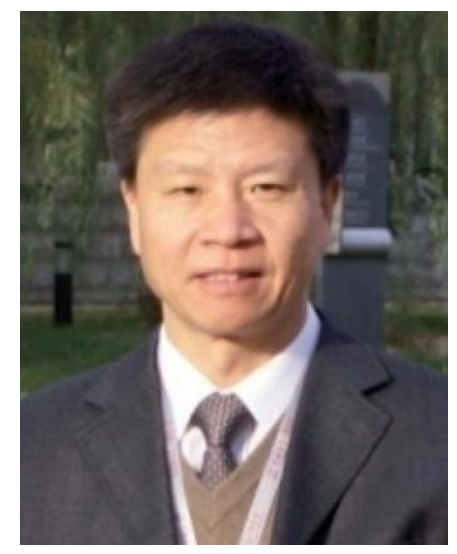

Shi-Gang Sun is a professor of chemistry at the State Key Laboratory of Physical Chemistry of Solid Surfaces, College of Chemistry and Chemical Engineering, Xiamen University, China. He received his Bachelor's degree in 1982 from Xiamen University and Doctorat d'Etat in 1986 from Universit e Pierre et Marie Curie (Paris VI), and carried out one year of postdoctoral research at the Laboratoire $\mathrm{d}^{\prime}$ Electrochimie Interfaciale du CNRS, France. He is currently a Fellow of the Royal Society of Chemistry, U.K., and a Fellow of the International Society of Electrochemistry. His research interests include electrocatalysis, electrochemical surface science, spectroelectrochemistry, and electrochemical energy conversion and storage.

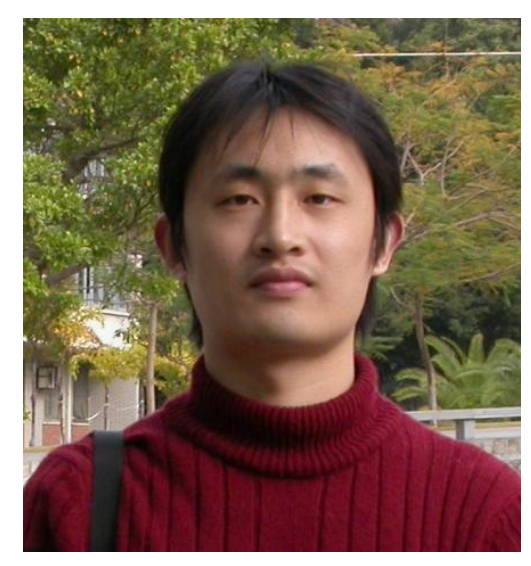

Minhua Shao earned his BS (1999) and MS (2002) degrees in chemistry from Xiamen University, and a $\mathrm{PhD}$ degree in materials science and engineering from State University of New York at Stony Brook (2006). He joined UTC Power in 2007 to 
lead the development of advanced catalysts and supports for PEMFC and PAFC. He was promoted to UTC Technical Fellow and Project Manager in 2012. In 2013, he joined Ford Motor Company to conduct research on lithium-ion batteries for electrified vehicles. He then joined the Hong Kong University of Science and Technology in the Department of Chemical and Biomolecular Engineering as an Associate Professor in 2014. He received the Supramaniam Srinivasan Young Investigator Award from the ECS Energy Technology Division (2014) and the Student Achievement Award from the ECS Industrial Electrochemistry and Electrochemical Engineering Division (2007). His research mainly focuses on electrocatalysis and advanced batteries. 


\section{Graphical abstract}
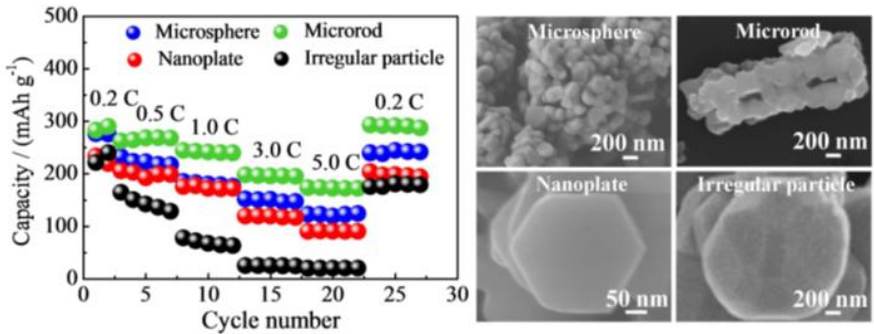